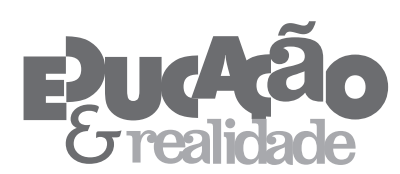

\title{
Educación contra Corriente en las Cárceles Latinoamericanas: la enseñanza vs el castigo
}

\author{
Hugo Rangel
}

RESUMEN - Educación contra Corriente en las Cárceles Latinoamericanas: la enseñanza vs el castigo. Promover la educación en las cárceles de hoy es difícil. Examinar las causas estructurales de esta situación compleja es el propósito de este artículo. Para producirlo se llevó a cabo un estudio de los documentos oficiales, las leyes y las prisiones fueron visitadas en varios países de América Latina. Entre los principales temas tratados, se incluyen: la impunidad y el fracaso del sistema de justicia; los límites del castigo; el castigo como ideología; imaginario punitivo y las contradicciones institucionales.

Palabras-clave: Educación en las Prisiones. Las Cárceles de América Latina. Enseñanza. Castigo

ABSTRACT - Education Against the Tide in Latin American Prisons: education versus punishment. Promoting education in prison is latterly a difficult task. This paper's objective is to examine the structural causes of this complex situation. We have accomplished a research on official documents and laws, and visited prisons in many Latin American countries, in order to produce this study. Among the many discussed issues, we may highlight: impunity and the failure of the justice system; the limits of punishment; punishment as an ideology; the punishment imagery and the institutional contradictions.

Keywords: Education in Prison. Latin American Prisons. Education. Punishment. 
Educación contra Corriente en las Cárceles Latinoamericanas

¿Cuántas condenas he visto más criminales que el crimen?

Montaigne

Promover la educación en prisiones en la actualidad es difícil. Examinar las causas estructurales de esta compleja situación es el objetivo de este texto. Para hacer este artículo se realizó una investigación de documentos oficiales, leyes y se visitaron prisiones en varios países de Latinoamérica. Mencionemos primero la crisis de los sistemas penitenciarios que señalan diversos estudios y ensayos. El hacinamiento, la sobrepoblación y sus nefastas consecuencias sobre las condiciones de los privados de libertad son constantes en los reportajes periodísticos sobre las prisiones. El objetivo de esta investigación fue de ir más allá de esta constatación que a veces se antoja redundante y ofrecer una explicación sobre el conjunto de la problemática. De esta manera se propone una reflexión que intenta explicar la condición de crisis y las políticas y los discursos que originan esas condiciones en las prisiones. En las visitas que realizamos a las prisiones constatamos las condiciones de hacinamiento, insalubridad, sobrepoblación y la falta de recursos y de servicios. Evidentemente, los programas educativos son más escasos de lo que los funcionarios afirman.

Cada prisión es una muestra clara de la situación crítica que viven las cárceles. Es evidente que el número creciente de presos empeora las condiciones físicas y además como lo han mostrado varios estudios al respecto, el estrés del personal de vigilancia e internos crece; así como las fricciones entre éstos. Pudimos constatar en la visita a El Salvador el nivel de estrés producto de las fricciones entre los internos y las requisas de las autoridades. Existen cada vez estudios sobre las prisiones que señalan la sobrepoblación y sus consecuencias negativas. Sin embargo y en virtud de esta situación es de vital importancia preguntarse: ¿Cuáles son los orígenes de este crecimiento? ¿Por qué las políticas que originan este crecimiento se mantienen a pesar de que no existe la capacidad de la infraestructura ni de recursos? ¿Porqué persiste la política de mayor encarcelación a pesar de que no ha garantizado mayor seguridad a la sociedad? ¿Porqué continuar incrementando la población de las prisiones si esto hace más difícil controlarlas? ¿¿Cuál es el impacto que tiene sobre los programas educativos en las cárceles?

Las respuestas a estas preguntas alimentan al argumento central de esta investigación. Resulta entonces pertinente presentar algunos elementos esenciales en torno al sistema de la justicia, ya que es bajo esta perspectiva que observamos las cárceles.

\section{Impunidad y Fallas del Sistema de Justicia}

Ya Aristóteles citaba el proverbio que dicta: "la justicia contiene todas las otras virtudes". Esto da una idea que la justicia ha sido considerada como central desde los orígenes de la filosofía occidental. De 
hecho los sistemas de justicia han definido en gran medida el desarrollo de las democracias modernas. Justamente la construcción de la democracia en América Latina depende en gran medida del desarrollo de los sistemas de justicia en la región.

Los diferentes estudios sobre las prisiones y de la justicia pone en evidencia que los sistemas de justicia del continente sufren fallas graves. Por ejemplo en Colombia se dice que se vive una "inseguridad jurídica” “[...] ya que la rama Jurisdiccional está totalmente anquilosada, no cuenta con suficientes recursos humanos, ni presupuestales, científicos técnicos y tecnológicos para aplicar una oportuna y eficaz justicia” (Echeverri, 2010).

Los países desarrollados (de mayor desarrollo democrático) han logrado constituir instituciones funcionales garantizando el acceso a la justicia a los ciudadanos. Esto es sin embargo un proceso continuo y perfectible. Por ejemplo, en los Estados Unidos, se han señalado recientemente fallas graves en los procedimientos forenses ${ }^{1}$; fallas pueden dar como resultado la impunidad de los homicidios ${ }^{2}$. Es evidente así que en América Latina estos procedimientos forenses podrían ser de gran utilidad para responder a los altos índices de criminalidad e impunidad.

Contrariamente a la novela de Tolstoi, Crimen y Castigo, la realidad en América Latina es más bien crimen sin castigo. La impunidad es un problema grave en América Latina. Los poderosos e influyentes tienen muchas menos posibilidades de estar en prisión que los pobres. Incluso funcionarios de varios de los países señalaron esta realidad producto del sistema social así como la corrupción y las fallas de las instituciones de justicia. Por ejemplo en Colombia se calcula que existe $98.5 \%$ de impunidad en ejecuciones ${ }^{3}$. En México, las proporciones de la impunidad son similares (Gertz, 2007). Asimismo en Argentina, algunos informes señalan la fragilidad del sistema judicial y la impunidad de quienes delinquen ${ }^{4}$.

La criminalidad ocupa espacios importantes en los medios de comunicación de la región. Además, la criminalidad es un tema central en las campañas políticas, en las preocupaciones de la población. Es notable que, independientemente que las estadísticas sobre la criminalidad varían entre los países, la percepción sobre el problema es central en la opinión pública.

Más aún existe en el continente un sentimiento - y constataciones cotidianas - en el sentido que las leyes no se aplican ${ }^{5}$. Por ejemplo, en Argentina se identificaron documentos diversos sobre la escasa aplicación de las leyes ${ }^{6}$. Además encuestas recientes muestran una muy baja satisfacción general del funcionamiento del sistema judicial en los países de América Latina (Latinobarómetro, 2009)7

Como lo mencionara el entonces funcionario del ministro de educación de Argentina, Tedesco, las leyes tienen una función programática más que normativa ${ }^{8}$. Esto indica que no solamente existe una per-

Educação \& Realidade, Porto Alegre, v. 38, n. 1, p. 15-32, jan./mar. 2013.

Disponível em: <http://www.ufrgs.br/edu_realidade> 
Educación contra Corriente en las Cárceles Latinoamericanas

cepción social de que las leyes no funcionan, sino que las autoridades conceden una función ajena a las leyes.

Se constató que en las cárceles no se cumplen los reglamentos y las leyes por lo menos de una manera puntual. Es decir, existe una distancia importante entre lo legislativo, la dinámica de los presos y la administración penitenciaria. Esta tiene su lógica y sus reglas propias, que se norman por dos justificaciones de incumplimiento de la ley: (a) por un lado existen las limitaciones presupuestarias y materiales. Varias veces se nos dijo que la distribución de los presos no era reglamentaria por falta de espacio y financiamiento y que no tenían dormitorios o no se daban cursos que indicaba la ley por falta de presupuesto. Asimismo en las cárceles mixtas improvisadas las mujeres sufren mayor tipo de violaciones de sus derechos ${ }^{9}$. (b) Los procedimientos de seguridad. En efecto, en Colombia se comentó con insistencia que los derechos de los presos - cursos o servicios - estaban sujetos a estrictos procedimientos burocráticos que tardaban tanto tiempo, que abarcaban el tiempo concedido al preso (una o dos horas). Sin embargo muchas veces se constató, por los testimonios de los empleados, que se trataba de burocracia, más que de seguridad. En las visitas que realizamos a los centros constatamos esta tardanza burocrática que incluía, sellos, autorizaciones, auscultación, firmas y verificaciones innecesarias de documentos.

Las cárceles son entonces una expresión de la injusticia social, no un mecanismo para establecer la justicia. Como lo mostró un estudio en Chile, que para la mayoría de la población, las personas que se encarcelan pertenecen a los barrios más modestos. Así percibe a la justicia de ese país como clasista y privilegia a quienes tienen el poder. Esto significa una mirada negativa de la justicia chilena y en particular las cárceles, ya que $76 \%$ de los entrevistados estimaron que "siempre van a ser escuelas formadoras de delincuentes” (Llano, 2011).

En este contexto, los profesionales que laboran en las prisiones se ven confrontados a realidades complejas. Principalmente los docentes que trabajan en las prisiones son de por si políticos que perciben cuando se debe andar para mejorar una democracia (Freire, 1993 p. 63).

\section{Los Límites del Castigo}

¿Porqué castigar un culpable, si no hay ningún bien que se pueda sacar de su punición? Se preguntaba Diderot (2008). Esta pregunta es pertinente en el contexto latinoamericano de hoy ya que existe un castigo exagerado en los sistemas de justicia ${ }^{10}$. Sobretodo si se toma en cuenta que las políticas en materia de atención penitenciaria son oficialmente la readaptación social. Las penas en América Latina son significativamente más extensas que en Europa, particularmente la región escandinava, y Canadá. Es de suma importancia subrayar que estos países cuentan con menores índices de criminalidad en el mundo. Como se señaló, en Latinoamérica la consecuencia lógica que ha acarreado la

18 Educação \& Realidade, Porto Alegre, v. 38, n. 1, p. 15-32, jan./mar. 2013. Disponível em: <http://www.ufrgs.br/edu_realidade> 
encarcelación como política de seguridad es el crecimiento de la población penitenciaria.

Una contradicción mayor de las prisiones en Latinoamérica estriba en la gran cantidad de presos sin condena, procesados. Esto significa que en varios países más de la mitad de la población penitenciaria no ha recibido un proceso definitivo que los declare culpables o inocentes y que establezca una pena en consecuencia ${ }^{11}$. Este fenómeno es una expresión de graves fallas estructurales en el sistema de justicia, no solamente una 'sistema legal lento' como se menciona a menudo. Las inmensas poblaciones de presos de 'manera preventiva' engrosan las filas de las prisiones.

Por otra parte, las políticas contra el tráfico y consumo de drogas han tenido un impacto sobre las poblaciones penitenciarias. Por ejemplo, en Brasil casi el $20 \%$ de la población de las prisiones purgan condenas relacionadas al tráfico de drogas (Población que se triplicó en los últimos 5 años) ${ }^{12}$. Es decir, hay una correlación directa entre las políticas penitenciarias punitivas y la llamada lucha contra el narcotráfico.

\section{El Castigo como Ideología: el imaginario punitivo}

A lo largo de la investigación se hizo patente que a pesar de la voluntad política de mejorar el sistema penitenciario; existe una ideología del castigo per se. Esta ideología podemos llamarla imaginario punitivo y consiste en la idea de que hay que castigar a los criminales (1) más allá de las consideraciones legales. (2) Como la única forma de atacar la delincuencia. De esta manera no es prioritaria una política para mejorar las prisiones porque socialmente se cuestiona el hecho de invertir o asignar fondos públicos a las prisiones. En efecto, a pesar de las deficiencias detectadas en las prisiones, un obstáculo mayor estriba en la fuerza de la ideología del castigo. La población percibe a las prisiones como auténticos purgatorios. En este sentido, la situación crítica de las prisiones no causa interés de la población. Es bien conocida la crítica de Foucault (1975) a la prisión como una institución de control social. Sin embargo la lectura de esta crítica es justamente que la prisión debe concebirse más como un ente de justicia que como un ente de control. Este es un desafío central para las prisiones en América Latina.

El populismo ha propiciado que en la mayoría de los países se plantee de manera insistente el restablecimiento de la pena de muerte. El imaginario punitivo es claramente percibido en los medios de comunicación como una respuesta a la violencia que en diferentes niveles y manifestaciones se vive en el continente. De esta manera se proponen y aprueban penas de mayor encarcelamiento con la suposición que constituirá un elemento disuasivo para los delincuentes ${ }^{13}$.

En este contexto se observó a lo largo de la investigación el endurecimiento de las penas de diversos delitos, entre ellos los que se relacionan con la droga. Incluso en Perú ${ }^{14}$ se castigan delitos menores.

Educação \& Realidade, Porto Alegre, v. 38, n. 1, p. 15-32, jan./mar. 2013.

Disponível em: <http://www.ufrgs.br/edu_realidade> 
Educación contra Corriente en las Cárceles Latinoamericanas

El narcotráfico se ha convertido en un fenómeno que ha profundizado el imaginario punitivo. En efecto, ha existido una diabolización del fenómeno que se ataca con la encarcelación de posesión o cualquier vínculo con las drogas. En los medios de comunicación se identificó un tratamiento cada vez más maniqueo, sobretodo en Colombia, Brasil y México, en el que la droga no se percibe como un problema social y de salud pública, sino una lucha maniquea entre 'buenos y malos' como se presentó en los medios de comunicación y el discurso oficial. En la lógica punitiva, los narcotraficantes no merecen la aplicación de la ley, sino un castigo severo y ejemplar. Al reclamar incluso que la cárcel es insuficiente y costosa, se sugiere la pena de muerte. En efecto, cientos de comentarios en los sitios de Internet de periódicos de la región reclamaban la muerte y la tortura para narcotraficantes y criminales en general.

De esta manera, aún cuando se presume que en el continente se ha erradicado la pena de muerte de las legislaciones de la región, es evidente que la 'pena máxima' ha ganado no solamente amplia simpatía de la gente, sino incluso goza de cierta legitimidad social debido a este imaginario punitivo. Es decir, en la opinión pública se justifica como una herramienta viable para atacar la criminalidad. Esta percepción puede ser corroborada por diferentes encuestas que recientemente se han realizado sobre la pena de muerte en Latinoamérica ${ }^{15}$. Además, cabe mencionar que no pocos políticos han promovido esta opción para explotar esa visión punitiva ${ }^{16}$.

Las deficiencias de los sistemas judiciales contribuyen a la visión simplista punitiva. Por ejemplo en México en el marco de la estrategia gubernamental contra el tráfico de drogas, las diferentes corporaciones y el ejército aprendieron a más de 100 mil personas como sospechosas de delitos vinculados al narcotráfico. Sin embargo como no se acreditaron las pruebas suficientes para condenarlos, solamente en $28 \%$ de los detenidos se reunieron pruebas para proceder a un juicio correspondiente ${ }^{17}$. Es decir, se liberó a los sospechosos a causa de una integración deficiente de los expedientes de los detenidos. Sin embargo para la gente esto representa una evidencia que los jueces y la justicia en general dejan libres a los delincuentes.

Por otra parte se identificó que algunas noticias que informaban sobre la muerte de presos en Venezuela, México y El Salvador eran celebradas por las personas que comentaban las noticias. Es sobresaliente que entre los cientos de comentarios fue prácticamente nula la condena. Por el contrario, muchos ciberlectores justifican una línea dura porque los jueces los liberarán. Otros se quejaban que encarcelarlos resultaba muy caro para los contribuyentes. Es decir, la tortura y la pena de muerte se avizoran como substitutos de los sistemas de justicia y sus fallas. Algunas veces incluso se apoyan las muertes de presuntos criminales a mano de autoridades sin importar su legalidad o moralidad. Asimismo, en esta lógica punitiva se apoya hacer justicia por propia mano. 
Cabe destacar la percepción de la violencia está sobrevalorada. Por ejemplo en Uruguay, un país con índices de violencia menores en el continente $^{18}$, según una encuesta indicó que $75 \%$ de la población opinó que la seguridad pública "estaba mal”. Además 68\% de los encuestados opinó que hay que "proteger la seguridad pública aunque se afecten los derechos y las garantías de los delincuentes y de los presos"19.

En este contexto, incluso la noción de los derechos humanos se encuentra bajo el ataque del imaginario punitivo. En efecto, muchos de los comentarios en Internet sobre noticias que informaban sobre violaciones de los derechos humanos afirmaban que los presos no merecían los derechos humanos. Otros pretendían que los promotores y los organismos de derechos humanos eran "instrumentos de los delincuentes". Incluso en algunos eventos que asistimos, varias personas afirmaron que los delincuentes tenían demasiados derechos. En Brasil, se comentó que debido a la oposición al término derechos humanos, algunos profesionales y académicos preferían hablar del "cumplimiento de las leyes” refiriéndose así a las leyes que garantizan esos derechos.

Esta percepción es de suma importancia, toda vez que durante las visitas realizadas a la prisiones tanto los presos como los profesionales hicieron patente las carencias de defensa legal que tienen los presos y por lo tanto éstos no disfrutan por una parte los derechos que les confieren tanto los leyes locales como los acuerdos internacionales sancionados por prácticamente todos los países de la región. Por otra parte, las carencias de apoyo legal afecta la defensa que cada preso requiere para su caso. La defensa legal pública es importante ya que la mayoría de los presos no cuenta con recursos económicos para solventar gastos en procedimientos legales farragosos, complejos y poco transparentes que se caracterizan en América Latina. Esto explica que justamente un gran número de los presos sean pobres.

El endurecimiento de las penas se debió en particular a leyes que atacan el narcotráfico. En efecto, a lo largo de las visitas constatamos la tendencia señalada por documentos oficiales y estudios regionales: un crecimiento significativo de personas que purgan penas relativas al tráfico de estupefacientes. Por ejemplo en Brasil se incrementó la población a un $20 \%$ de la población penitenciaria en un lapso de 5 años ${ }^{20}$.

Como lo mencionan algunos estudios, las penas impuestas por ofensas menores relativas al narcotráfico son desproporcionadamente altas en prácticamente toda América Latina. Además existe un abuso de la detención preventiva para los sospechosos de estos delitos ${ }^{21}$.

"El magistrado que castiga y que reprende debe olvidarse de sí mismo y solamente preocuparse del interés público", decía Cicerón. En efecto, el interés público debe prevalecer en la sanción de infractores de la ley. Este espíritu se percibe en países de mayor desarrollo democrático, como en Europa occidental. Por ejemplo en Canadá un criterio para liberar a un preso incluso antes y durante su proceso judicial -incluidos

Educação \& Realidade, Porto Alegre, v. 38, n. 1, p. 15-32, jan./mar. 2013.

Disponível em: <http://www.ufrgs.br/edu_realidade> 
quienes son acusados de narcotráfico - consiste en que no represente un peligro para la sociedad ${ }^{22}$.

Como observamos, la lógica del castigo obedece a un imaginario punitivo que nada tiene que ver con la justicia ni la reparación del daño. Esta lógica obedece más al populismo y a la venganza que a la solución del problema de la violencia. De esta manera la educación en las cárceles es fundamental para revertir esta lógica y ofrecer a los presos opciones para su desarrollo personal. Contra la lógica punitiva, es conveniente que los gobiernos de América Latina respondan con la lógica de la educación. Independientemente de la infracción o delito, tratar al preso como un ser humano que merece acceder a la educación. Es la educación que eventualmente lo cambiará y no el castigo - la tortura y el maltrato.

\section{Contradicciones Institucionales}

Constatamos a lo largo de las entrevistas, las contradicciones de las instituciones. En efecto, en el transcurso de la investigación se percibió una actitud gubernamental que contrasta con la percepción popular de las cárceles. El lenguaje fue incluso en el caso de Argentina y se le llamó "contexto de encierro", término políticamente correcto. Solamente algunos gobiernos como el de Uruguay han conservado el término popular de cárcel. Por lo que respecta a México la apelación de Centros de Readaptación Social (CERESO) está claramente rebasado por la situación crítica de los centros.

La percepción sobre las prisiones es así bastante negativa. Es conocida la noción de perogrullo que la cárcel es una escuela del crimen. No podía ser de otra forma cuando incluso muchas administraciones de prisiones son incapaces de clasificar los presos por tipo de sanciones ${ }^{23}$. Además es evidente que cuando se encarcela indiscriminadamente, a quienes cometen sanciones menores se les encarcela con criminales. La percepción de la cárcel como institución reformadora y de rehabilitación de delincuentes es baja, incluso en Chile, país con prisiones menos congestionadas y con un sistema de justicia reformado ${ }^{24}$.

De esta manera la terminología oficial no corresponde a la realidad. Existe una retórica que muestra una burocracia ajena a la crisis de las prisiones y que incluso niega dicha situación. En efecto, en el transcurso de la presente investigación se constató una gran dificultad de las autoridades para mostrar una apertura a las críticas de los sistemas de prisiones. Se observó un oficialismo e incluso el reclamo de algunos representantes gubernamentales sobre la inclusión de señalamientos críticos sobre la situación de las prisiones ${ }^{25}$.

Los objetivos el tratamiento penitenciario es la resocialización en Colombia ${ }^{26}$, en México es la reinserción del sentenciado ${ }^{27}$, anteriormente la readaptación. En Perú el sistema penitenciario es la reeducación, 
rehabilitación y reincorporación del interno a la sociedad ${ }^{28}$. En Chile el objetivo es la recuperación de las personas. En Ecuador rehabilitar a las personas privadas de libertad. ¿Qué denota la manía de la utilización del prefijo RE en el discurso oficial latinoamericano? Más allá de las contradicciones propias de la terminología, que han sido ampliamente discutidas en el continente, es pertinente subrayar que las leyes y los objetivos tendientes a tratar a los presos e integrarlos a la sociedad han fracasado ${ }^{29}$. Los casos exitosos de 'reinserción' que comentan los funcionarios son evidentemente una minoría muy reducida.

Observamos que existe una aguda crisis de los centros penitenciarios producto de un crecimiento exponencial del número de presos. ¿Qué hacen los gobiernos de la región para atacar este problema? Identificamos varias tendencias, por ejemplo, (1) la privatización de los centros. Ante la falta de recursos simplemente se opta por privatizar servicios y el conjunto de la administración de las cárceles. Chile desarrolló esta política pero algunos países como Perú han iniciado la privatización ${ }^{30}$. Sin embargo esta política tiene como resultado la gestión basada en costos y beneficios y no en la seguridad ni la inserción de los internos. (2) Otra respuesta es la construcción de prisiones. Se crea así una industria de construcción que reproduce el problema, ya que como el crecimiento persiste, la construcción es progresiva. (3) Algunos países como México han implementado proyectos como la utilización de brazaletes electrónicos para substituir el encarcelamiento. Sin embargo esta opción es demasiado costosa y controlada por las compañías que venden este producto. Así, esta estrategia no solamente es limitada, sino que no ofrece por si solo un tratamiento de inserción del preso. (4) No hay respuesta, solo un seguimiento pasivo de la tendencia de crecimiento. Desgraciadamente esta última es la tendencia dominante. Las poblaciones de presos crecen ante la impotencia de las autoridades de las prisiones. Como vemos, la educación no representa una opción para numerosas autoridades. Además con esta tendencia, las posibilidades de ofrecer actividades educativas a los presos se reducen.

Los funcionarios gubernamentales insistieron que hay que tomar en cuenta las acciones y no solamente observar los problemas y los aspectos negativos. Constatamos que estos programas para lograr los objetivos de reinserción existen pero son insuficientes. Se ofrecen a una minoría de los presos ${ }^{31}$. El estudio previo (Rangel, 2009) mostró que los programas educativos no solamente son insuficientes, sino aislados y discontinuos y en general tradicionales y poco adaptados a la realidad de las cárceles. Ahora hemos constatado además que no existen en la mayoría de las prisiones tratamiento psicológico que es básico para llevar a cabo la inserción que supuestamente se proponen las autoridades. Cabe destacar que en países desarrollados este tipo de tratamiento ha reducido sensiblemente los niveles de reincidencia delictiva. Asimismo los programas educativos, culturales y deportivos reducen no solamente la violencia en las prisiones, sino reducen la reincidencia.

Educação \& Realidade, Porto Alegre, v. 38, n. 1, p. 15-32, jan./mar. 2013.

Disponível em: <http://www.ufrgs.br/edu_realidade> 
Montesquieu dijo que "Una vez que los principios del gobierno son corrompidos, las mejores leyes se convierten en malas y se vuelven contra el Estado" (2009, p. 196). Es precisamente lo que se aprecia en América Latina ante las leyes e iniciativas en el medio penitenciario. Estas no se concretizan debido a deficiencias institucionales y principios corrompidos por el imaginario punitivo.

La información sobre las prisiones es sensible, por lo que hubo una clara reticencia a proporcionar datos y documentos. Una de las contradicciones mayores en las prisiones de América Latina es la falta de transparencia. La información es fragmentaria, incompleta y no existen a menudo los mismos criterios para realizar estadísticas sobre las prisiones. Esta circunstancia justificó la visita y el diálogo directo con presos, empleados y funcionarios y no depender así de estadísticas incompletas e inconsistentes.

Además, cabe subrayar que sobre los informes oficiales que presentan los países no se perciben los problemas graves de la prisiones. Estos informes y el discurso de los funcionarios dan cuenta de los programas, de la organización y objetivos de los ministerios. Los funcionarios niegan así los defectos del sistema de los penales y de los sistemas de justicia. Cabe mencionar que en el transcurso de la investigación se solicitó a los gobiernos de los países que presentaran una experiencia exitosa cultural o educativa de inserción de los internos. Sin embargo insistieron en presentar los programas oficiales. Esto evidenció el escaso contacto que las autoridades tienen con las actividades concretas en las prisiones.

El contacto con el resto de la familia ha mostrado que no solamente ayuda a los presos, sino que ayuda a la familia. Las colonias de presos como el de Las Islas Marías (en México) ha mostrado que los vínculos familiares y la ausencia de rejas han contribuido a una prisión pacífica y con una reincidencia delictiva mínima. Sin embargo justamente la tendencia punitiva descarta este tipo de experiencias ya que por una parte se busca punir y por otra la explosión de la población penitenciaria dificulta este tipo de estrategias.

\section{Finalmente, ¿Cuál es la Función de la Cárcel?}

Las sociedades latinoamericanas deben preguntarse para qué quieren tener presa a la gente. Como mencionamos, el discurso oficial que oímos de funcionarios, leyes y documentos oficiales indican que las cárceles son centros de readaptación. Es decir constituyen un periodo preparatorio de la reinserción social. Sin embargo las condiciones en las que se encuentran las prisiones no concuerdan con estos objetivos. Los programas concretos atienden en los mejores casos a una minoría de la población. En las visitas se constataron falta de recursos. La inmensa mayoría de los presos hablaron de las carencias de salud, de espacios y 
de problemas con el personal de vigilancia. Algunos expusieron casos de corrupción y pagos indebidos.

Es pertinente mencionar que el trabajo en las prisiones se observa cada vez más como la única vía para llevar a cabo los objetivos de inserción. Sin embargo observamos que se da prioridad a las empresas para que exploten a los presos como mano de obra muy barata y a veces gratuita. Incluso en los gobiernos que promueven programas educativos, se promueven estas empresas de mano de obra barata.

Hay que señalar que las instituciones muestran negligencia en informar a los presos sobre su situación legal y no se les asiste e informa de manera adecuada sobre sus procesos. Cabe destacar que las autoridades se mostraron renuentes a informar a los presos sobre los procedimientos legales por temor oficial de que se evidencien deficiencias y contradicciones. Incluso se observó una posición renuente por parte de las autoridades a incluir cursos que traten el proceso penal por temor a protestas. Este oficialismo y censura de los contenidos educativos pone en entredicho la procuración de justicia de autoridades ${ }^{32}$.

Otro aspecto abordado por funcionarios de algunos países, principalmente de Perú y Ecuador, fue la problemática del tratamiento de presos de alta peligrosidad, principalmente los jefes de mafias de tráfico de drogas. Estas autoridades mostraron evidentes contradicciones y dilemas: su idea de imponer penas y tratamientos severos y la necesidad de otorgar beneficios señalados por la ley (educación y contacto continuo con su familia). En varios países se vivieron protestas de presos que les fueron suspendida la televisión, a veces el único pasatiempo que ofrecen los penales.

Sin embargo se identificó un problema de mayor dimensión: una debilidad de las administraciones de los penales de imponer el orden y la ley. Ante esta debilidad, se impone la lógica del más fuerte. Así, los presos se ven acosados por los grupos delictivos que ejercen una autoridad informal que suple a la oficial. De esta manera en muchas prisiones impera la lógica del poder y del dinero. Quien tiene dinero, cuenta con mayores privilegios en las cárceles. Existen informaciones que señalan la existencia de prisiones en las que los grupos delictivos controlan la gestión y gobierno de dichas prisiones.

Este endurecimiento del tratamiento al interior de las prisiones contrasta con los exitosos programas que se implementan en los centros de países desarrollados. Por ejemplo, los proyectos de juegos, deportes y actividades culturales han significado una disminución de tensiones e incidentes en las prisiones de algunos países europeos como España y Holanda.

Así, en la situación de aguda crisis en la que se encuentran las prisiones no contribuye a una reinserción o readaptación social. Por otra parte, tampoco responden a las expectativas del discurso de seguridad, ya que como vimos, las prisiones están sobrepobladas y eso no significa

Educação \& Realidade, Porto Alegre, v. 38, n. 1, p. 15-32, jan./mar. 2013.

Disponível em: <http://www.ufrgs.br/edu_realidade> 
que las sociedades latinoamericanas sean más seguras. Pues como hemos observado, la criminalidad se ha incrementado en la mayoría de los países de la región.

Como observamos, los índices de criminalidad son muy altos en el continente y la percepción social indica que la situación empeora. De hecho la delincuencia es percibida como el principal problema de la región (Latinobarómetro, 2010) ${ }^{33}$. Por otra parte las prisiones son focos de violencia y, como se mencionó, existe una percepción negativa en el sentido que no alberga a muchos criminales debido a la impunidad. De esta manera está claro que las prisiones no cuentan con una legitimidad como instituciones de justicia.

Es una tarea de gran importancia para los gobiernos de América Latina clarificar las funciones de las prisiones como instituciones de justicia. Al hacer esta redefinición, las actividades educativas son complementarias y compatibles con el sistema de justicia. Si las cárceles son más que lugares de confinamiento, los programas educativos son esenciales para construir instituciones de justicia. En los documentos oficiales e incluso las leyes se indica que las prisiones son rehabilitadoras, sin embargo son pocos los presos que reciben educación. Es decir, en los hechos las cárceles no rehabilitan a los internos.

\section{Las Cárceles como Espacio de Excepción de la Ley}

Como se mencionó, las prisiones visitadas y los estudios consultados muestran que no se cumplen los preceptos legales, tanto locales como internacionales. Prueba de ello es que el gobierno de México y los de América Latina ratificaron la declaración de Principios básicos para el tratamiento de los reclusos de Naciones Unidas adoptada en 1990. Sin embargo podemos afirmar que existen violaciones flagrantes que distan mucho de ser aisladas. Asimismo consultamos las legislaciones que rigen los centros penitenciarios de los países de América latina y se observó que estipulan principios similares a los que señala la declaración de la $\mathrm{ONU}^{34}$.

Por ejemplo, dicha declaración señala que (Art. 1) "todos los reclusos serán tratados con el respeto que merecen su dignidad y valor inherentes de seres humanos”. El artículo 5 de la declaración señala que "todos los reclusos seguirán gozando de los derechos humanos y las libertades fundamentales". No obstante, hemos constatado que la dignidad y los valores humanos son difícilmente protegidos en un contexto de crisis generalizado de los centros penitenciarios. De esta manera se señalan violaciones de los derechos humanos en las prisiones de la región como las vejaciones, los maltratos y a veces la tortura.

El Art 2 señala que "no existirá discriminación por motivos posición económica”, sin embargo justamente describimos que hay evidencias y percepciones que indican una discriminación de la población 
pobre que no puede pagar servicios legales y a menudo la corrupción que la rodea.

La declaración mencionada en su artículo 6 establece que "todos los reclusos tendrán derecho a participar en actividades culturales y educativas encaminadas a desarrollar plenamente la personalidad humana". Pero como constatamos, solamente una minoría - entre 10 y $18 \%$ de la población la más de las veces - goza de cursos y talleres en los centros penitenciarios. Incluso los reglamentos de algunos países representan obstáculos para cumplir este objetivo educativo y cultural ${ }^{35}$.

Sin embargo, en la prisión la educación significa restituir un derecho. En efecto, la mayoría de los presos en todo el continente tiene bajos niveles de escolaridad. Muchas veces no estudiaron porque no tuvieron oportunidad de hacerlo o porque sus condiciones de marginalidad impidieron que aprovecharan alguna oportunidad. De esta manera, la educación en prisiones representa una manera de restituir un derecho.

El artículo 8 de dicha declaración señala: "se crearán condiciones que permitan a los reclusos realizar actividades laborales remuneradas y útiles que faciliten su reinserción en el mercado laboral del país y les permitan contribuir al sustento económico de su familia y al suyo propio". Sin embargo, como vimos el trabajo no es remunerado y cuando lo es, no es suficiente para el sustento familiar. Además, insistimos que en general el trabajo no permite la inserción, ya que se trata de trabajos manuales que no requieren calificación.

La misma declaración (artículo 9) establece que "los reclusos tendrán acceso a los servicios de salud". Sin embargo constatamos que los presos contaban con servicios médicos insuficientes (a veces inexistentes) que aunado a las condiciones deficientes de las prisiones, las condiciones de salud de los internos se degradan.

La declaración señala (artículo 10) que "se crearán condiciones favorables para la reincorporación del ex recluso a la sociedad". No obstante pocas prisiones cuentan con programas que hagan un seguimiento de la inserción social de los presos una vez que son liberados. Contrariamente a las estrategias en países desarrollados que cuentan con programas de transición, en América Latina se libera sin programas ni preparación previa.

Camus nos decía que el estado de derecho no debe detenerse en las puertas de la cárcel. Lo lamentable en América Latina es que como observamos, la ley y el estado de derecho no tienen poder ni adentro ni afuera de las prisiones.

Como observamos, tanto las leyes locales como las declaraciones internacionales no se cumplen en la realidad. Aún cuando el discurso de los gobiernos ha sido el de que existe el estado de derecho, en la sociedad existe un alto índice de impunidad que desmiente esta suposición. En este contexto, la cárcel se ha constituido como un lugar donde es lógico que no exista el respeto a la ley.

Educação \& Realidade, Porto Alegre, v. 38, n. 1, p. 15-32, jan./mar. 2013.

Disponível em: <http://www.ufrgs.br/edu_realidade> 
Educación contra Corriente en las Cárceles Latinoamericanas

Para revertir esta situación, es necesario promover la educación en las prisiones. Al reivindicar el derecho a la educación no se demanda solamente acceso a un curso X, sino a tener un derecho a la educación, a sus servicios de salud y por lo tanto a una educación para la salud que prevenga enfermedades así como a condiciones sanitarias mínimas para mantenerse en salud. Es decir a una educación integral que incluya enseñar los derechos como presos y los derechos para su estatuto legal. Una educación que atienda los derechos como seres humanos. Asimismo no solamente el preso necesita educación, los vigilantes o custodios requieren de una formación para tratar convenientemente al preso. Mandela (1991) afirmó que para un preso su relación con el custodio es más importante que con un director de la prisión o el ministro de justicia de un país. Un custodio bien formado puede respetar los derechos humanos de un interno y entre ellos justamente el de ser educado. Asimismo las autoridades deben reconocer a la educación y actuar consecuentemente. Muchos profesores se han quejado de las malas condiciones de trabajo, las injusticias de que son objeto y la "desvergüenza de los salarios”, como decía Freire (1993, p. 62) ${ }^{36}$. Es decir, aún cuando hay prisiones en las que se ofrecen cursos, no se da la importancia que amerita a la educación.

En la medida en que las autoridades valoren la importancia de la educación en prisiones, su trascendencia para construir una justicia, en esa medida se le dará a la educación el apoyo y el seguimiento que requiere. Asimismo se ofrecerán los cursos necesarios para mujeres, sus niños que viven en prisión, actividades culturales, formación para el trabajo... es decir toda la diversidad de educación que se necesita en las prisiones.

\section{Consideraciones Finales}

Observamos que las cárceles son focos de violencia. Sin embargo muchas autoridades prefieren comprar tecnología o tomar medidas para contener la violencia. Sin embargo pocas veces se concibe a la educación dentro de las estrategias oficiales para llevar la paz a las prisiones. Numerosos testimonios en Latinoamérica hicieron mención a una mejoría de las condiciones con programas educativos y culturales. En este sentido, la educación en las cárceles es esencial para humanizarlas y combatir la violencia.

Contra las corrientes conservadoras dominantes que imponen una lógica punitiva; contra los populismos que piden el castigo sin misericordia a cualquier persona que viole la ley; contra los pretextos y las demagogias que se niegan a invertir en la educación y en las prisiones; contra las inercias políticas y las reticencias neoliberales a invertir en la educación de adultos; resulta fundamental la reivindicación de la educación en prisiones. 
Ciertamente las actividades educativas no pueden resolver por sí mismas todos los problemas que confrontan las prisiones, porque como observamos, estos problemas son la expresión de fallas en los sistemas de justicia. Sin embargo las prácticas educativas no solamente son complementarias, sino que se inscriben en una lógica de la justicia y la legalidad. Y justamente para respetar esta legalidad las autoridades de las prisiones deben garantizar su derecho a la educación.

Como se expuso, el desmedido crecimiento de la población en las cárceles de América Latina se debe en gran medida a la tendencia de encarcelar (por más tiempo y a la menor provocación) como estrategia para atacar la violencia. Sin embargo, si se compara con los países con mayor desarrollo democrático, estos países practican una estrategia opuesta. Es decir, encarcelan menos tiempo y por una gama mucho menor de infracciones. Como consecuencia directa, las prisiones son más humanas (Pratt, 2007). Además, como se mencionó, estos países ofrecen múltiples programas de intervención en los centros penitenciarios (de educación y tratamiento psicológico).

A todas luces, estos países desarrollados despliegan políticas más generosas para las personas que han infringido la ley, aunque evidentemente lo hacen también con aquellas que respetan la ley. Como dijo acertadamente Cicerón (2011), en donde no hay generosidad, no hay justicia (p. 34). Justamente hemos mostrado que el imaginario punitivo imposibilita no solamente la generosidad de instituciones y de las políticas, sino que niega los derechos básicos que le confiere la ley a un preso para defenderse o para vivir dignamente en una prisión. Justamente en esta lógica de generosidad es en la que se inscribe el respeto al derecho a la educación de los presos.

\section{Notas}

1 Fallas atribuidas a que instituciones privadas realizan dichos exámenes forenses.

2 Post Mortem, NPR y PBS, Frontline, 2011. Asimismo este estudio mostró la necesidad de revisar los exámenes forenses oficiales que encubren empleados gubernamentales, principalmente policías.

3 Ver por ejemplo Alston, Ph. Report of the Special Rapporteur on Extrajudicial, summary or arbitrary executions. Mission to Colombia. ONU, 31 de marzo 2010.

4 Ver por ejemplo EU denuncia la corrupción oficial y la impunidad en Argentina. El País, 09 feb. 2011.

5 Por ejemplo, la encuesta IPSOS - Universal, 57\% de los encuestados estimó que la ley no se aplica en México (agosto 2007).

Educação \& Realidade, Porto Alegre, v. 38, n. 1, p. 15-32, jan./mar. 2013.

Disponível em: <http://www.ufrgs.br/edu_realidade> 
6 Por ejemplo, Las leyes no se cumplen del Programa de legislaciones y derecho a la comunicación (15 mar. 2009).

7 Disponible en : <http://www.latinobarometro.org/latino/latinobarometro. jsp>.

8 Conferencia inaugural del seminario educación en contextos de encierro, el caso de Argentina. Buenos Aires, mayo 2007.

9 Por ejemplo, en México 263 cárceles cuentan con población femenil, de los cuales solamente 9 son centros femeniles. SSP, 2009.

10 Por ejemplo en México en 2010 el Senado aprobó sanciones hasta por 90 años a secuestradores.

11 Población en las cárceles sin recibir condena: Argentina 55\%, Perú 68\%; Uruguay $63 \%$; Ecuador $56 \%$; México $42 \%$, Bolivia y Paraguay $75 \%$. Cabe mencionar que la cifra oficial de Brasil fue cuestionada por un funcionario del ministerio de justicia de ese país, quien la estimó mucho mayor.

12 En Brasil, el número de presos por tráfico de drogas pasó de 32.880 (en 2005) a 91.037 en 2009. Infopen, Ministerio de Justicia/ DEPEN, Brasilia, 2009

13 Una encuesta en El Salvador indica que $94.8 \%$ de la población pide aumentar los castigos contra el crimen (2007). En México 93.6\% (2005).

14 Por ejemplo en Perú se aprobó una ley (septiembre 2009) que se castiga con cárcel a los reincidentes de delitos menores, anteriormente se les sancionaba con trabajos comunitarios.

15 En México, 71\% apoyó la pena de muerte (El Universal, 27-04-2007). En Chile $63 \%$ de los encuestados la apoyó (La Tercera, 08-08-2009). En Brasil, 55\% la apoyó (Folha de S. Paulo, 06-08-2008). En Perú 80\% de la población la aprobó (El Mundo, 16-08-2010). En El Salvador 74.8\% votaron por imponer dicha pena para ciertos delitos (Mitofsky, 2007).

16 Por ejemplo en México el Partido "Verde Ecologista" hizo una nutrida campaña basada en la pena de muerte en las elecciones de 2009. En Perú, el presidente apoyó la pena de muerte en su gobierno 2006-2011. En Guatemala los opositores de derecha han exigido la reintroducción de la pena de muerte (vigente pero que no se aplica desde 1998). En El Salvador la Gran Alianza Nacional propuso al legislativo en 2010 para aplicar la pena de muerte en el país.

17 Sistema Institucional de Información Estadística de la Procuraduría General de la República. México, 2011.

18 Con una tasa de homicidio de 4,4 (por 100 mil habitantes) se ubica en el lugar 34 de violencia mundial. Mapa de Violencia, São Paulo, 2011

19 Encuesta organizada por la consultora Factum y publicada por el Espectador de Uruguay, 18-07-2008.

20 En Brasil el número de presos por tráfico de drogas pasó de 32.880 (en 2005) a 91.037 en 2009. Infopen, MJ/DEPEN, Brasilia, 2010.

21 Sistemas sobrecargados - Leyes de drogas y cárceles en América Latina.

22 La Comission nationale des libérations conditionnelles es una instancia del gobierno federal canadiense es un puente entre la vida en prisión y la vida en sociedad. El criterio para otorgarla es la seguridad de público.

23 Este problema se percibió en El Salvador. Incluso en prisiones donde los 
presos estaban clasificados, la sobrepoblación motivó que los nuevos presos se mezclaran.

24 Según ICSO, 54.3\% de los encuestados opinó que la cárcel no era la mejor forma de rehabilitar (Opinión Pública y Justicia en Chile, 2005-2010, Universidad Diego Portales).

25 Tal fue el caso de los representantes de Argentina y México en la investigación previa sobre los programas educativos e incluso algunos cuestionaron la autoría de dicho estudio.

26 Código Penitenciario y Carcelario de Colombia, ley 65 de 1993.

27 Artículo 18 de la Constitución Política de México (reformado en 2008).

28 Artículo 139 de la Constitución Política del Perú, 1993.

29 Podría afirmarse que las fallas del tratamiento penitenciario no dependen necesariamente de la terminología convencional, ya que países democráticamente avanzados utilizan la misma a veces la misma terminología. Por ejemplo, Canadá utilizan la readaptación y reinmersión social. Mientras otros no, como el de Dinamarca que se centra sobre la normalización.

30 La prisión de Huaral funciona de forma privada bajo el gobierno de A. García (2010).

31 En Brasil se informa que $18 \%$ de presos está inscrito a diversos cursos (Ministerio de Justicia). En México según la SSP los inscritos representan 10\% aproximadamente.

32 Estos reclamos se escucharon tanto en profesionales como en presos en México y Colombia.

33 Según Latinobarómetro, desde 2004 ha aumentado de $9 \%$ a 27\% la percepción de la delincuencia como el principal problema hasta 2010 (en la encuesta más reciente).

34 Por ejemplo, se consultó la ley de readaptación social de los sentenciados de México, la ley penitenciaria de El Salvador (1997), la ley Nacional de Educación de Argentina (2006), la ley del Régimen Penitenciario de Venezuela (2000) y Brasil. Regras Mínimas para o Tratamento do Preso no Brasil. Brasília: Conselho Nacional de Política Criminal e Penitenciária, 1995.

35 Por ejemplo, en México la libertad de lectura es restringida por algunos reglamentos.

36 Además en unos países como en México hay docentes (asesores) que no perciben sueldo, ya que trabajan como voluntarios.

\section{Referencias}

ARGENTINA. Ley Nacional de Educación de Argentina, 2006.

BRASIL. Regras Mínimas para o Tratamento do Preso no Brasil. Brasília: Conselho Nacional de Política Criminal e Penitenciária, 1995.

BRASIL. Infopen. Ministerio de Justicia/ DEPEN, Brasilia: 2009.

CICERÓN. Traité des Devoirs. Paris: Flammarion, 2011.

COLOMBIA. Código Penitenciario y Carcelario de Colombia, ley 65 de 1993.

Educação \& Realidade, Porto Alegre, v. 38, n. 1, p. 15-32, jan./mar. 2013.

Disponível em: <http://www.ufrgs.br/edu_realidade> 
DIDEROT, Denis. Pensées Philosophiques. Paris: Flammarion, 2008.

ECHEVERRI, Iván. La pena de muerte. El Colombiano, Medellín, 19 oct. 2010.

EL SALVADOR. Ley Penitenciaria de la República de El Salvador, 1997.

FOUCAULT, Michel. Surveiller et Punir. Paris: Gallimard, 1975.

FREIRE, Paulo. Cartas a Quien Pretende Enseñar. México: Siglo XXI, 1993.

GERTZ, Manero. Seguridad e Justicia: si se puede. México: Universidad de las Américas, 2007.

GOIRAND, Camille. Violences et Controle de la Violence au Brésil en Afrique et à Goa. Paris: Karthala, 2003.

HANEY, Craig. The wages of prison overcrowding: Harmful psychological consequences and dysfunctional correctional reactions. Journal of Law \& Policy, Washington University, v. 22, p. 265-293, 2006.

LLANOS, A. Estudio de Seguridad Pública. Chile: Universidad Central de Chile, 2011.

MANDELA, Nelson. Long Walk to Freedom. New York: Back Bay Books, 1995.

MÉXICO. Ley de readaptación social de los sentenciados de México, 1971.

MONTESQUIEU, Baron de. De l'Esprit des Lois. Paris: Flammarion, 2008.

PRATT, John. Scandinavian Exceptionalism in Era of Penal Excess. Londres: Oxford University Press, 2007.

RANGEL, Hugo. Mapa Latinoamericano de Educación en Prisiones: notas para el análisis de la situación y la problemática regional. París: Centre international d'études pédagogiques, 2009.

ROUSSEAUX, y De Weirt. Violences Juveniles Urbaines en Europe. Histoire d'une construction sociale. París: Presses universitaires de l'université de Louvain, 2011

VENEZUELA. Ley del Régimen Penitenciario de Venezuela, 2000.

WAISELFISZ, Julio Jacobo. Mapa de Violencia 2011: os jovens do Brasil. Instituto Sangari : São Paulo, 2011.

Hugo Rangel é professor e pesquisador da Universidade de Quebec - Montreal (Canadá), consultor do Observatório Internacional da UNESCO sobre Educação em Prisões e membro do Sistema Nacional de Pesquisadores do México. Tem experiência na área de política de Educação em Prisões na América Latina. País: México/Cidade do México.

E-mail: hugo.rangel@mail.mcgill.ca 